\title{
School-based nutrition education to improve children and their mothers' knowledge on food and nutrition in rural areas of the Philippines
}

\author{
Idelia G. Glorioso*, Milflor S. Gonzales \& Andrea Marie P. Malit \\ Food and Nutrition Research Institute, Department of Science and Technology
}

\begin{abstract}
Introduction: Nutrition education among school children and their mothers is an opportunity to promote lifelong healthy eating behaviours to improve their nutrition and well-being. The present study determined the effectiveness of nutrition education modules in improving children and their mothers' knowledge on food and nutrition. Likewise, changes in attitude and behaviour among children were also determined. Methods: Five nutrition education modules were developed with key messages on healthy plate, fruits and vegetables, protein sources, nutrientdense sources of energy, and water and healthy beverages. Grades 2 and 3 students received 60 hours of nutrition education with a duration of 25 minutes per session. Students were divided into two groups: (1) nutrition education alone $(n=83)$ and (2) nutrition education with feeding $(n=83)$. Simultaneously, a total of nine onehour nutrition education sessions were conducted among mothers, following the same five modules taught to the students. Mothers were also grouped according to their child's group. Results: Student participants in both groups exhibited improvements in mean scores on knowledge, attitude, and behaviour (KAB) from baseline to end line. Based on results of mothers' classes, mean post-test scores of participants were significantly higher than mean pre-test scores in both groups. Group 1 had a higher increase in score from $67.2 \pm 32.8$ at pre-test to $71.8 \pm 33.7$ in post-test. Conclusion: The developed nutrition education modules were effective in teaching children proper nutrition. Incorporation of these modules into the $\mathrm{K}$ to 12 curriculum will emphasise importance of proper nutrition in early childhood. Moreover, mothers' classes can be an effective way to bridge the gap between school and community nutrition interventions.
\end{abstract}

Keywords: School-based nutrition education, nutrition knowledge scores, mothers' nutrition classes

\section{INTRODUCTION}

Stunting and underweight among Filipino school children of 6-10 years old are still public health problems of high severity with prevalences of $31.1 \%$ and $31.2 \%$, respectively, as reported in the 2015 Updating National Nutrition
Survey of the Department of Science and Technology-Food and Nutrition Research Institute (DOST-FNRI) (FNRIDOST, 2015). Overweight and obesity are also growing problems for this age group with a prevalence of $8.6 \%$.

Nutrition plays a vital role in ensuring

\footnotetext{
${ }^{*}$ Corresponding author: Idelia G. Glorioso

Supervising Science Research Specialist, Food and Nutrition Research Institute Department of Science and Technology, DOST Compound, Bicutan, Taguig City Tel: (63) 8837-20-71 local 2287; Fax: (63) 8837-29-34; E-mail: maideliag@yahoo.com doi: https://doi.org/10.31246/mjn-2020-0004
} 
full potential physiological and cognitive growths among children. Eating habits, which also develops early in life, can also affect health and nutritional status of children. Thus, teaching nutrition at an early age can be an opportunity to promote lifelong healthy eating habits and other behaviours to improve nutrition and well-being of school children.

Schools are the most effective and efficient venue to reach out to young children, school staffs, families and community members via nutrition education. In addition, children and adolescents spend the most time in schools (Aldinger \& Jones, 1998; PerezRodrigo et al., 2001). Several studies examined the effects of school-based nutrition and health education in improving nutrition and health-related knowledge, attitude and behaviour (KAB) of children related to healthy eating, diet, physical activity, and increased consumption of fruits and vegetables (Wall et al., 2012; Watts, 2012; Evans et al., 2016). Other studies looked into the duration, length and frequency of nutrition education interventions in relation to increasing fruits and vegetables consumption, increasing physical activity, promoting healthy eating and reducing overweight and obesity among school children (Morgan et al., 2010; Prelip et al., 2012; Rosario et al., 2012; Moss et al., 2013). Based on a systematic review across 7218 studies about the effectiveness of school-based interventions among children and adolescents aged 6-18 years old, most school-based interventions (82.0\%) have the potential to improve dietary and physical activity behaviours and to prevent unhealthy body weights in lowand middle-income countries. To reach full potential, process evaluations that document programme implementation should be conducted (Verstraeten et al., 2012). Another systematic review which identified effective behavioural models and behavioural change strategies showed a similar outcome and suggested that interventions should also be focused on developing children's and parents' perceived competence at making dietary and physical changes (Nixon, 2012). Evidence suggests that schoolbased nutrition education is effective in improving nutrition knowledge and attitudes of school children. Nutrition education in the classroom is intended to convey nutrition information and change unhealthy attitudes to motivate students in establishing healthy eating practices and to teach positive skills.

In the Philippines, schools recently transitioned to a new curriculum with a 13-year basic education called the $\mathrm{K}$ to 12 Programme. The K to 12 Programme covers Kindergarten and 12 years of basic education (six years of primary education, four years of Junior High School, and two years of Senior High School [SHS]). In this curriculum, nutrition is taught in the first quarter of each school year among Grades 1-4 students as part of their Health subject. For Grade 1, nutrition topics focus on healthful and less healthful foods, consequences of eating less and good eating habits. Nutrition topics for Grade 2 include healthy foods and the body, and guides in eating a balanced diet such as the food pyramid and healthy plate. For Grade 3, good nutrition and health, and Nutritional Guidelines for Filipinos (NGF) are topics included in the curriculum guide. Reading food labels and food safety principles are topics discussed in Grade 4 (Department of Education, 2016). Given that the curriculum is particularly new, learning materials can still be enhanced so that students acquire in-depth knowledge, skills, and attitudes, particularly on nutrition. Developing a good nutrition 
education module is important to create an effective nutrition education (Anwar et al., 2018).

Most of the local nutrition interventions by the government are focused only on children as programme participants. However, in reality, mothers and caregivers play an important role in achieving proper nutrition for children. Extending nutrition interventions to mothers will have a positive impact on health and nutrition. Improved nutrition knowledge of mothers can be applied in their households, thus preventing malnutrition among children (Sukandar et al., 2015).

In August 2017, the DOST-FNRI undertook a comprehensive one-year school-based programme on food and nutrition, which includes feeding underweight school children and nutrition education among targeted school children and their mothers. The programme, Forging Public-IndustrySociety alliance: A Program United for Healthier Kids (PISO for Healthy Kids), consisted of four components, namely, Project 1 - Translation of Pinggang Pinoy for Children into Adequate Meals, Project 2 - Translation of Pinggang Pinoy for Children into Adequate Meals - Recipe Development, Project 3 - Nutrition Education, and Project 4 - Evaluation Research.

Project 3 of the programme - Nutrition Education aimed to develop nutrition education modules for use by Grades 2 and 3 teachers of four selected public elementary schools, and to conduct nutrition education campaigns among Grades 2 and 3 students of selected public schools and their mothers or caregivers. Therefore, the present study determined the effectiveness of these developed nutrition education modules in improving children and their mothers' knowledge on food and nutrition. Likewise, changes in behaviours among children were also determined.

\section{MATERIALS AND METHODS}

\section{Development of nutrition education modules}

Workshop

A workshop was conducted among teams of DOST-FNRI nutritionistdietitians and teachers from Daang Hari Elementary School, Bicutan, Taguig City, Philippines to develop comprehensive nutrition education modules that are in line with the $\mathrm{K}$ to 12 curriculum. Five nutrition education modules were developed based on the pre-determined key messages of the researchers.

Pre-testing of nutrition education modules These nutrition education modules were pre-tested to determine their attractiveness, comprehensibility, acceptability, and self-involvement of the modules for Grades 2 and 3 students, and to assess if the materials given to the teachers were sufficient for the conduct of nutrition education classes. Pretesting activities were done in elementary schools of both urban and rural areas. These elementary schools had similar characteristics with the study schools, but were not study participants.

The study employed random pre-testing. Pre-tested lessons were representative of five modules. Out of the 29 lessons in each module, nine lessons were randomly selected for pre-testing. These pre-testing lessons were also representative of the different learning activities included in the modules like word search, true or false, and matching type. Nutrition education lessons that were to be pre-tested were given to the teachers in advance for familiarisation. Collaterals for the lessons like worksheets, posters, flash cards, big books, and puzzles were also given in advance to the teachers. Teachers demonstrated the lessons in the modules and conducted individual or group activities for the evaluation of 
the lessons. After the demonstration, the researchers conducted key informant interviews using a validated questionnaire developed by the researchers following the metrics of attractiveness, comprehensibility, acceptability and self-involvement.

\section{Study design and participants}

The study used a quasi-experimental design. The study participants were from the PISO for Healthy Kids programme who received nutrition education. A total of 1,788 Grades 2 and 3 students from four schools in Laguna, Philippines were included in the nutrition education sessions from August 2017 to March 2018. Among these students, 166 were considered eligible study participants based on criteria for age (7-9 years old) and nutritional status (underweight). The criteria for age were based on the age grouping of the Philippine Dietary Reference Intakes (PDRI). The eligible participants were the ones assessed based on changes in their KAB. Students were distributed into two groups: (1) nutrition education alone $(n=83)$ and (2) nutrition education with feeding $(n=83)$. Simultaneously, nutrition education sessions were conducted among mothers of these selected students, following the same five modules taught to the students. The groupings of the mothers were based on their child's grouping.

\section{The intervention}

\section{Implementation of nutrition education}

component

A training entitled "Teaching Nutrition for Healthier Kids" was conducted to capacitate the teachers for the ensuing conduct of nutrition education in selected schools in Bay and Calauan, Laguna, Philippines. A total of 51 Grades 2 and 3 teachers from Calauan and Bay Central Elementary Schools attended the training on July 24-25, 2017. A nutritionist emphasised important nutrition concepts in every module to ensure that the teachers understood the content of the modules. After discussions on the technical content of the modules, a teaching demonstration of the nine sessions in each module was done. The teacher-participants were grouped and asked to demonstrate the nine topics in each module. The facilitators and nutritionists gave comments and suggestions for further improvement in discussing the nutrition concepts. A follow-up meeting was conducted among Grades 2 and 3 teachers after completing each module. This was done to get feedback from the teachers on the use of these modules.

Copies of the nutrition education modules were given to the teachers, which served as their guide in teaching students. The teachers followed the modules provided by the project and used the collaterals for each module. The teachers taught the modules in their individual creative ways by adding more photos and drawings, and supplementing the modules with audiovisual presentations and videos.

The students were exposed to nutrition education topics through a 25-minute session totalling to 144 sessions (about 60 hours). There was a dedicated time slot for the 25-minute nutrition education session, and was conducted during school days (Monday to Friday). The nutrition sessions were not incorporated in the Health and Science subject because in the existing curriculum, nutrition concepts are only discussed in the first quarter of each school year. The four schools conducted different number of hours of nutrition education sessions, ranging from 57.50 hours to 60.42 because of varying school activities and class suspensions due to typhoons and holidays (Table 1). Two nutritionist-researchers were assigned to ensure that the nutrition education sessions were conducted during school 
Table 1. Number of hours of nutrition education conducted per school, grade level and section

\begin{tabular}{|c|c|c|c|}
\hline Name of school & $\begin{array}{l}\text { Grade level and } \\
\text { section }\end{array}$ & $\begin{array}{l}\text { No. of hours } \\
\text { of nutrition } \\
\text { education }\end{array}$ & $\begin{array}{c}\text { Reasons for not completing } \\
\text { the } 60 \text { hours nutrition } \\
\text { education }\end{array}$ \\
\hline \multirow{10}{*}{$\begin{array}{l}\text { Sto. Tomas Elementary } \\
\text { School, Calauan, Laguna }\end{array}$} & Gr. 2-Emerald* & 60.42 & - \\
\hline & Gr. 2-Pearl & 60.42 & - \\
\hline & Gr. 2-Ruby & 60.42 & - \\
\hline & Gr. 2-Amethyst & 60.42 & - \\
\hline & Gr. 3-Rizal* & 57.92 & Additional school activities \\
\hline & Gr. 3-Lapu-lapu & 57.50 & Additional school activities \\
\hline & Gr. 3-Bonifacio & 57.50 & Additional school activities \\
\hline & Gr. 3-Del Pilar & 57.92 & Additional school activities \\
\hline & Gr. 3-Mabini & 56.67 & Additional school activities \\
\hline & Gr. 3-Silang & 57.50 & Additional school activities \\
\hline \multirow{6}{*}{$\begin{array}{l}\text { Dayap Eelementary School } \\
\text { Annex, Calauan, Laguna }\end{array}$} & Gr. 2- Marangal* & 58.33 & Additional school activities \\
\hline & Gr. 2-Matapat & 58.33 & Additional school activities \\
\hline & Gr. 2-Matiyaga & 57.92 & Additional school activities \\
\hline & Gr. 2-Magalang & 57.92 & Additional school activities \\
\hline & Gr. 2-Masikap & 57.92 & Additional school activities \\
\hline & Gr. 3-Matulungin & 58.33 & Additional school activities \\
\hline \multirow{5}{*}{$\begin{array}{l}\text { Bay Central Elementary } \\
\text { School, Bay, Laguan }\end{array}$} & Gr. 2-Luna* & 58.33 & Early school vacation \\
\hline & Gr. 2-Amorsolo & 58.33 & Early school vacation \\
\hline & Gr. 2-Tolentino & 57.50 & Early school vacation \\
\hline & Gr. 2-Joya & 57.50 & Early school vacation \\
\hline & Gr. 2-Francisco & 57.92 & Early school vacation \\
\hline $\begin{array}{l}\text { Kabaritan Elementary } \\
\text { School, Bay, Laguna }\end{array}$ & Gr. 2-Polite & 57.50 & Early school vacation \\
\hline
\end{tabular}

days and to observe how the teachers conducted the lessons for improvement of its conduct in succeeding months.

\section{Implementation of mothers' classes}

The mothers' classes were done either once or twice a month alongside the nutrition education classes for students. DOST-FNRI nutritionist-researchers conducted a total of nine one-hour lectures among mothers using the same topics in the nutrition education modules taught to the students. The mothers' classes were designed to ensure that the topics covered were targeted to the mothers by presenting nutrition concepts through interactive ways and various formats like giving practical examples, asking mothers to share their experiences in meal planning and preparation, and conducting games and contest among the group. The mothers' classes were conducted so that key learning concepts taught to their children would also be learnt by the mothers. This way, reinforcement of key nutrition messages was addressed. Also, feedbacks on how their children were faring in terms of knowledge gained through nutrition education were also determined. 
The nine sessions of mothers' classes covered all topics in the modules. One session of mothers' class comprised of 14 to 15 topics in the module taught to the students. This meant that one module was equivalent to 2 sessions of mothers' class. One session of mothers' class ran for an hour, inclusive of preand post-tests.

Each session included a pre-test before the start of the session to measure the baseline knowledge, followed by the nutrition lecture and a post-test after the session. Each session tackled different topics based on the five modules as detailed below:

- Module 1: Go, Grow and Glow + Water/Beverage in every plate (Pinggang Pinoy)

$\circ$ Session 1

- Three food groups (Topics/ Sessions 1-8)

- Healthy kids need water (Topics/Sessions 9-11)

○ Session 2

- Pinggang Pinoy (Healthy Plate) for children, 6-9 years old (Topics/Sessions 12-19 including review of concepts)

- Module 2: Eat fruits and vegetables of varied colours (the colourful plate) ○ Session 3

- Eat fruits and vegetables of every colour (Topics/Sessions 1-16)

- Food choices from the fruit group and vegetable group (Topics/Sessions 17-19)

- Session 4

- Planting seeds for healthier eating (Topics/Sessions 2026)

- Why are fruits and vegetables important in a child's diet (Topics/Sessions 27-29)

- Module 3: Consume various kinds of protein sources

$\circ$ Session 5
- The different protein sources (Topics/Sessions 1-14)

○ Session 6

- The functions of protein for the body (Topics/Sessions 1521)

- Healthy proteins for healthy eating (Topics/Sessions 2229)

- Module 4: Consume more nutrientdense sources of energy

○ Session 7

- Food sources of energy (cheap and concentrated sources of energy) (Topics/Sessions 1-6)

- What are nutrient-dense foods (Topics/Sessions 7-15)

- Session 8

- Nutrient-dense or energydense foods (Topics/Sessions 16-23)

- The taste palette

- How sweet or salty are you

- Why are nutrient-dense foods important in a child's diet (Topics/Session 24-29)

- Smart snacking

- Module 5: Drink recommended glasses of water and complement it with nutritious beverages

Session 9:

- The water cycle (Topics/ Sessions 1-6)

- Forms and sources of water (Topics/Sessions 7-16)

- Drink enough healthy fluids (Topics/Sessions 17-22)

- Better beverages choices

- Kid-friendly beverages

- Why are water and other nutritious beverages important in a child's diets

\section{Data collection}

The study used validated questionnaires developed specifically for the study. KAB of children and mothers/caregivers were collected at baseline and end line. The 
study also used the modified version of the Child and Diet Evaluation Tool (CADET) questionnaire developed by the Nutrition Epidemiology Group, Division of Epidemiology and Biostatistics of the University of Leeds for behaviour change indicators among student participants.

For mothers' classes, a 10-item validated questionnaire was used to measure increase in knowledge on the nutrition concepts taught. The 10-item questionnaire used in the mothers' classes for pre- and post-tests were not the same as what was used for the children in terms of knowledge. All the pre- and post-test questions for the mothers' classes were derived from the modules or lectures. Questionnaire used for the children were developed based on the modules taught to the students.

\section{Data analysis}

Data collected were encoded, processed and analysed using the Statistical Package for Social Sciences (SPSS) for Windows versions 16 and 20. Paired $t$-test was used to compare means between groups and between periods for each group. A $p$-value $<0.05$ was considered significant for the tests performed.

The changes in the mean scores on KAB among children were compared within and between groups by period of data collection. The changes in mean pre-test and post-test scores of mothers were also compared between groups. For the mean score on behaviour among children and mothers, the 4-option choices (i.e. always; often; seldom; and never) were recoded into 3-option choices (i.e. 'always' and 'often' combined; seldom; never).

The mean scores for CADET attitude were determined. The 5-option choices (i.e., strongly agree; agree; neutral; strongly disagree; and disagree) were recoded into 3-option choices ('strongly agree' and 'agree' combined; neutral; 'strongly disagree' and 'disagree' combined).

\section{Ethical considerations}

Prior to programme implementation, the research protocols were approved and cleared on May 31, 2017 by the FNRI Institutional Ethics Review Committee (IERC) with the code FIERC-2017-007.

The teachers and others/caregivers of the students were orientated on the objectives and details of the study. Participants were assured of the confidentiality of information collected in connection with the study. Mothers / caregivers signed the consent forms for participation in the study during the orientation. Students' assents to participate in the study were also sought with the assistance of the teachers, who explained and guided them in filling-up the Assent Forms.

\section{RESULTS}

A total of five nutrition education modules were developed with key messages as follows: 1. Go, Grow and Glow + Water/ beverage in every plate (Pinggang Pinoy); 2. Eat fruits and vegetables of varied colours (the colourful plate); 3. Consume various kinds of protein sources; 4. Consume more nutrient-dense sources of energy; and 5. Drink recommended glasses of water and complement it with nutritious beverages. The modules were revised accordingly based on the comments and suggestions from the teachers (Table 2).

The results showed that student participants in both groups exhibited an improvement in mean scores on knowledge from baseline to end line, but the improvement was only significant in Group 2 (55.7 \pm 7.3 to $58.6 \pm 4.7, p=0.01)$. In terms of attitude, increments in the scores were observed at end line for children in both groups. In terms of 


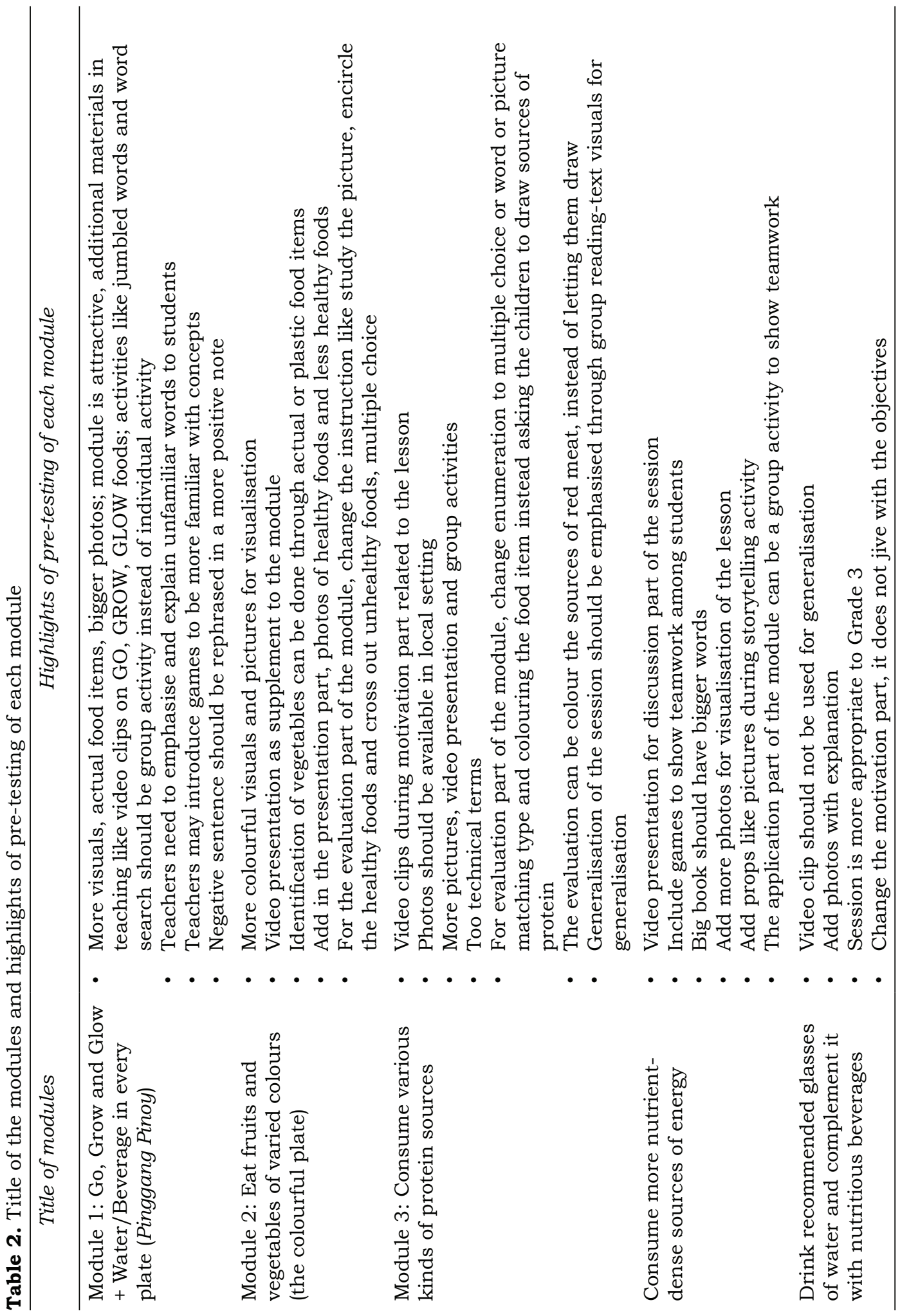


Table 3. Mean scores on KAB of children at baseline and end line*

\begin{tabular}{lcc}
\hline & \multicolumn{2}{c}{ Scores (Mean \pm SD) } \\
\cline { 2 - 3 } Period & Group 1 & Group 2 \\
\hline Knowledge & $13.7 \pm 4.3$ & $13.6 \pm 4.5$ \\
Baseline & $16.6 \pm 4.1$ & $17.5 \pm 5.3$ \\
End line & $<0.001^{*}$ & $<0.001^{*}$ \\
$p$-value (base-end) & & \\
Attitude & $63.3 \pm 7.7$ & $63.4 \pm 7.6$ \\
Baseline & $64.8 \pm 7.7$ & $65.8 \pm 8.4$ \\
End line & 0.110 & 0.050 \\
$p$-value (base-end) & & \\
Behaviour & $56.4 \pm 5.1$ & $55.7 \pm 7.3$ \\
Baseline & $56.8 \pm 5.7$ & $58.6 \pm 4.7$ \\
End line & 0.648 & 0.001 \\
$p$-value (base-end) &
\end{tabular}

Source: Project 4: Evaluation Research under the Programme PISO for Healthier Kids ${ }^{*} p<0.05$ represents statistical significance (paired $t$-test)

changes in behaviour, there was an increase in mean scores of both groups from baseline to end line, but with significant difference only in Group 2 (Table 3).

As presented in Table 4, the post-test scores of participants in both groups were significantly higher than their pre-test scores. Group 1 had a higher increase in score from $67.2 \pm 32.8$ at pretest to $71.8 \pm 33.7$ in post-test. However, only five sessions among those in Group
1 had significant increases from pre-test to post-test scores. Contrariwise, all but one session among those in Group 2 had scores which increased significantly from pre-test to post-test. Moreover, participants obtained the highest scores in sessions 1, 4 and 8 in both groups. These topics were generally about the three food groups and water, importance of eating fruits and vegetables, and nutrient-dense foods, respectively.

Table 4. Pre- and post-tests scores $($ mean $\pm S D)$ of participants of mothers' classes

\begin{tabular}{lccccccc}
\hline \multirow{2}{*}{ Session } & \multicolumn{3}{c}{ Group 1 } & & & \multicolumn{3}{c}{ Group 2} \\
\cline { 2 - 3 } \cline { 6 - 7 } & Pre-test & Post-test & $p$ & & Pre-test & Post-test & $p$ \\
\hline Session 1 & $13.4 \pm 0.9$ & $14.6 \pm 0.6$ & $0.001^{*}$ & & $13.6 \pm 0.9$ & $14.1 \pm 0.6$ & $0.002^{*}$ \\
Session 2 & $12.9 \pm 0.7$ & $13.4 \pm 1.2$ & 0.168 & & $12.9 \pm 0.9$ & $13.5 \pm 0.6$ & $<0.001^{*}$ \\
Session 3 & $12.8 \pm 0.9$ & $13.3 \pm 1.4$ & 0.180 & & $12.9 \pm 1.4$ & $13.8 \pm 1.6$ & $0.001^{*}$ \\
Session 4 & $13.4 \pm 1.2$ & $14.1 \pm 0.8$ & $0.015^{*}$ & & $13.3 \pm 1.6$ & $14.3 \pm 0.8$ & $<0.001^{*}$ \\
Session 5 & $12.6 \pm 0.8$ & $12.7 \pm 1.4$ & 0.866 & & $12.5 \pm 1.2$ & $13.4 \pm 1.1$ & $<0.001^{*}$ \\
Session 6 & $12.6 \pm 1.8$ & $13.3 \pm 1.7$ & 0.108 & & $12.1 \pm 2.1$ & $13.7 \pm 1.5$ & $<0.001^{*}$ \\
Session 7 & $11.5 \pm 1.9$ & $13.5 \pm 1.5$ & $0.004^{*}$ & & $12.0 \pm 1.2$ & $13.6 \pm 1.5$ & $<0.001^{*}$ \\
Session 8 & $13.0 \pm 1.2$ & $14.0 \pm 1.0$ & $<0.001^{*}$ & & $13.4 \pm 1.1$ & $14.0 \pm 1.0$ & $0.011^{*}$ \\
Session 9 & $12.9 \pm 1.5$ & $13.7 \pm 1.6$ & $0.033^{*}$ & & $13.2 \pm 1.6$ & $13.7 \pm 1.1$ & 0.065 \\
Total & $67.2 \pm 32.8$ & $71.8 \pm 33.7$ & $<0.001^{*}$ & $49.1 \pm 36.3$ & $52.2 \pm 32.8$ & $<0.001^{*}$ \\
\hline
\end{tabular}

${ }^{*} p<0.05$ represents statistical significance (paired $t$-test) 


\section{DISCUSSION}

Nutrition education is for teachers and students. Teachers play an important role in helping students develop good eating habits. As teachers learn more about food and nutrition, they can better convey nutrition information to their students.

Prior to the conduct of the nutrition education campaign, teachers were trained to capacitate them in teaching nutrition. In the study done by Stage et al. (2016), providing teachers with professional developments like training and integrative resources and activities may result in improved self-efficacy in teaching nutrition, but the amount of training needed to improve this should be considered. Perceived self-efficacy is the people's beliefs about their capabilities to produce effects (Bandura, 1994). A study by Ross \& Bruce (2007) attributed that professional developments likely led to increased knowledge and confidence in teachers. Therefore, Falhman et al. (2011) found that as self-efficacy was related to teacher's effectiveness in teaching nutrition, thus providing them with continual training should be pursued.

In the present study, the nutrition education sessions were taught as a separate subject and had a dedicated time slot in each school depending on the approved schedule by the school principal. A total of 144 sessions were conducted during school days totalling to 60 hours, which was more than the recommended number of 40-50 hours needed to exhibit behavioural changes based on previous studies (Connell, Turner \& Mason, 1985; Contento, 1995; Perera et al., 2015). The nutrition sessions were not incorporated in the Health subject because nutrition concepts were only discussed in the first quarter of the school year as specified in the $\mathrm{K}$ to 12 curriculum. Our study is in contrast with the study of Perera et al. (2015), which suggested that nutrition education can be implemented by integrating it in the Math, Science, and/ or English subjects.

The results showed that children in all study groups exhibited significant improvements in their mean scores on KAB from baseline to end line. This is consistent with the study conducted by Connell et al. (1985) that few hours of classroom instructions were needed to produce knowledge effects, while more hours of classroom education to produce attitude and practice effects. To establish stable effects for knowledge, attitude and practice, about 40-50 classroom hours are needed. Another study confirmed that they needed 15 classroom hours to have an effect on knowledge, and 50 hours per year to bring about changes in attitudes and behaviours (Contento et al., 1995).

A total of nine sessions or nine hours of nutrition education among mothers were conducted following the same five modules taught to the students. Nutrition education is beneficial in increasing mothers' nutritional knowledge and improving their children's nutritional status. Empirical evidence suggests that the greater the knowledge of mothers on health and nutrition, the better is the overall quality of their children's diet (Blaylock, Variyam \& Lin, 1999). A recent study conducted by Mbogori \& Murimi (2019) strengthens the importance of nutrition education with results stating that maternal nutrition knowledge improved after a nutrition education intervention. Another study also found that nutritional status of children with and without supplementary feeding improved significantly when their mothers received nutrition education twice a week for three months (Roy et al., 2005). Although these studies showed significant results among children under five years old only, continuous conduct of 
nutrition education targeted at mothers would still have a positive impact to their nutritional knowledge and the nutritional status of their children as they age.

The above mentioned studies were all conducted in low- to middle-income countries which have high prevalences of malnutrition. Moreover, programmes which aim to address malnutrition problems usually target these countries. The Catholic Relief Services, in partnership with the World Bank, implemented a four-year programme called the "Community-Driven Nutrition Improvement Programme" or CDNIP focusing on mothers and their children to improve nutrition in targeted communities of Timor-Leste. The programme worked with the communities to educate young mothers and pregnant women on the importance of nutrition and healthy lifestyles. Through this programme, families are increasing the variety of fruits and vegetables they eat with meals, more regularly including sources of protein, and mothers learn about the importance of eating different types of foods which will help their children grow (World Bank, 2017).

\section{CONCLUSION}

The nutrition education modules developed by the project can greatly help teachers in teaching proper nutrition and good food habits to school children. For the mothers' classes, the nutrition education campaign was effective in improving the nutrition knowledge of mothers. In addition, the study showed improvements in KAB of students using the developed nutrition education modules.

However, some limitations were still encountered. Firstly, there was a lack of trainings conducted among the teachers due to time constraint, but the researchers were able to conduct feedback meetings after completion of each module. Some classes were not able to reach a total of 60 hours for the sessions because of varying school activities and class suspensions due to typhoons and holidays.

The study recommends that nutrition is included in the $\mathrm{K}$ to 12 curriculum as a separate subject from Music, Arts, PE, and Health (MAPEH) subjects, instead of limiting to one quarter of the school year. In addition, nutrition education modules developed can be used to teach children on proper nutrition. Incorporation of these modules in the curriculum can be a way to introduce proper nutrition in early life of children.

Moreover, the study underscores the mother-child pairing for nutrition education to be sustained and that lessons taught to students must be the same with those taught to mothers for follow-through of learnings in the home. Other than teaching children, setting up mothers' classes can be an effective way to bridge the gap between school and community nutrition interventions.

\section{Acknowledgement}

The authors would like to acknowledge the support of Ms. Divorah V. Aguila, DOST-FNRI Planning Officer IV and Project Coordinator of PISO for Healthy Kids for facilitating the smooth conduct of the project; Creative Publications Unit (CPU) staff for assisting in the conduct of pre-testing of five nutrition education modules; and Ms. Julieta B. Dorado, DOST-FNRI Supervising Science Research Specialist and Project 4 Component Leader for allowing us to use some results from the evaluation component. The authors also acknowledge the participation and help of the teachers and children involved in the study.

\section{Authors' contributions}

IGG, principal investigator, conceptualised and designed the study, led the data collection in Bay and Calauan, Laguna, prepared the draft and final manuscript, reviewed the final manuscript before submission to Malaysian Journal of Nutrition; revise the manuscript based on the comments of two reviewers; MSG, conceptualised and designed the study; assisted in drafting of the manuscript, reviewed the final manuscript before submission 
to Malaysian Journal of Nutrition; AMPM, data analysis and interpretation, assisted in drafting of the manuscript, proofread the manuscript and assisted in the revision of manuscript based on the comments of two reviewers.

\section{Conflict of interest}

The authors declare no conflict of interest in this study. PISO for Healthy Kids project was supported by Nestle Inc. Philippines. The funding organisation did not exert influence on the study methodology and interpretation of the findings.

\section{References}

Aldinger C \& Jones JT (1998). Healthy nutrition: an essential element of a health-promoting school. In Healthy Nutrition: an essential element of a health-promoting school. World Health Organization, Geneva.

Anwar K, Hardinsyah H, Aries M \& Navratilova $\mathrm{H}$ (2018). Nutrition education module and workbook development for primary school children. International Conference on Community Development 1(1):141-147.

Bandura A (1994). Self-efficacy: The exercise of control. Freeman, New York.

Blaylock J, Variyam JN \& Lin BH (1999). Maternal nutrition knowledge and children's diet quality and nutrient intakes. The Economic Research Service, US Department of Agriculture, Washington, DC.

Connell DB, Turner RR \& Mason EF (1985). Summary of findings of the school health education evaluation: Health promotion effectiveness, implementation, and costs. $J$ School Health 55(8):316-321.

Contento I, Balch GI, Bronner YL, Paige DM, Gross SM, Bisignani L, Lyte LA, Maloney SK, White SL, Olson CM, Swadener SS \& Randell JS (1995). The effectiveness of nutrition education and implications for nutrition education policy, programs, and research: a review of research. $J$ Nutr Educ 27:277-422.

Contento IR (2007). Nutrition education: linking research, theory, and practice. Jones \& Bartlett Learning, Burlington, Massachusetts.

Department of Education (2016). In: K-12 Curriculum Guide Health (Grade 1 to Grade 10). Department of Education, Republic of the Philippines. From http://depedbohol.org/v2/ wp-content/uploads / 2016/03/Health-CG_ with-tagged-math-equipment.pdf [Retrieved November 26 2019].
Evans A, Ranjit N, Hoelscher D, Jovanovic C, Lopez M, McIntosh A, Ory M, Whittlesey L, McKyer L, Kirk A, Smith C, Walton C, Heredia NI \& Warren J (2016). Impact of school-based vegetable garden and physical activity coordinated health interventions on weight status and weight-related behaviors of ethnically diverse, low-income students: Study design and baseline data of the Texas, Grow! Eat! Go!(TGEG) cluster-randomized controlled trial. BMC Public Health 16(1):973.

Fahlman M, McCaughtry N, Martin J \& Shen B (2011). Efficacy, intent to teach, and implementation of nutrition education increases after training for health educators. American Journal of Health Education 42(3): 181-190.

FNRI-DOST (2015). The Philippine Nutrition Facts and Figures 2015: Anthropometric Survey. Food and Nutrition Research Institute, Department of Science and Technology, Metro Manila.

Mbogori T \& Murimi M (2019). Effects of a nutrition education intervention on maternal nutrition knowledge, dietary intake and nutritional status among food insecure households in Kenya. Int $J$ Community Med Public Health 6(5):1831-1837.

Morgan PJ, Warren JM, Lubans DR, Saunders KL, Quick GI \& Collins CE (2010). The impact of nutrition education with and without a school garden on knowledge, vegetable intake and preferences and quality of school life among primary-school students. Public Health Nutr 13(11):1931-1940.

Moss A, Smith S, Null D, Long Roth S \& Tragoudas U (2013). Farm to school and nutrition education: Positively affecting elementary school-aged children's nutrition knowledge and consumption behavior. Child Obes 9(1):5156.

Nixon CA, Moore HJ, Douthwaite W, Gibson EL, Vogele C, Kreichauf S, Wildgruber A, Manios Y, Summerbell CD \& ToyBox-study group (2012). Identifying effective behavioural models and behaviour change strategies underpinning preschool-and school-based obesity prevention interventions aimed at 4-6-year-olds: a systematic review. Obes Rev 13:106-117.

Perera T, Frei S, Frei B, Wong SS \& Bobe G (2015). Improving nutrition education in US elementary schools: Challenges and opportunities. J Educ Prac 6(30): 41-50. 
Pérez-Rodrigo C, Klepp KI, Yngve A, Sjöström M, Stockley L \& Aranceta J (2001). The school setting: an opportunity for the implementation of dietary guidelines. Public Health Nutr 4(2b):717-724.

Prelip M, Kinsler J, Le Thai C, Erausquin JT \& Slusser W (2012). Evaluation of a school-based multicomponent nutrition education program to improve young children's fruit and vegetable consumption. J Nutr Educ Behav 44(4):310318.

Rosário R, Oliveira B, Araújo A, Lopes O, Padrão P, Moreira A, Teixeira V, Barros R, Pereira B \& Moreira $P$ (2012). The impact of an intervention taught by trained teachers on childhood overweight. Int $J$ Environ Res Public Health 9(4):1355-1367.

Ross J \& Bruce C (2007). Professional development effects on teacher efficacy: Results of randomized field trial. J Educ Res 101(1):5060.

Roy SK, Fuchs GJ, Mahmud Z, Ara G, Islam S, Shafique S, Sharmin S \& Chakraborty B (2005). Intensive nutrition education with or without supplementary feeding improves the nutritional status of moderately-malnourished children in Bangladesh. J Health Popul Nutr 320-330.

Stage VC, Roseno A, Hodges CD, Hovland J, Diaz S $\&$ Duffrin MW (2016). Implementation of a foodbased science curriculum improves fourthgrade educators' self-efficacy for teaching nutrition. Am J Health Educ 47(3):155-162.
Sukandar D, Khomsan A, Anwar F, Riyadi H \& Mudjajanto ES (2015). Nutrition knowledge, attitude and practice of mothers and children nutritional status improved after five months nutrition education intervention. Int J Sci Basic Appl Res 23:424-42.

Verstraeten R, Roberfroid D, Lachat C, Leroy JL, Holdsworth M, Maes L, \& Kolsteren PW (2012). Effectiveness of preventive schoolbased obesity interventions in low-and middleincome countries: a systematic review. Am J Clin Nutr 96(2):415-438.

Wall DE, Least C, Gromis J \& Lohse B (2012). Nutrition education intervention improves vegetable-related attitude, self-efficacy, preference, and knowledge of fourth-grade students. J School Health 82(1):37-43.

Watts SO, Piñero DJ, Alter MM \& Lancaster KJ (2012). An assessment of nutrition education in selected counties in New York state elementary schools (Kindergarten through fifth grade). $J$ Nutr Educ Behav 44(6):474-480.

World Bank (2017). In: Focusing on Mothers and their Children to Improve Nutrition in TimorLeste. From https://www.worldbank.org/en/ results / 2017/04/07/focusing-on-mothersand-their-children-to-improve-nutrition-intimor-leste [Retrieved November 26 2019]. 